\title{
BRIEF FOR A BUFFALO PARK
}

\section{by Allen Ronaghan, Consort, Alberta*}

The story of the efforts of the Canadian government to save the Plains Bison from extinction used to be well known. While the Wainwright Buffalo Park was maintained a curious public could visit the area and see the buffalo for themselves. Articles about the park and its buffalo appeared constantly in newspapers and magazines and circulars were distributed to visitors to the park. Best of all, thousands of people went home realizing that an animal, once in danger of disappearing forever, had been spared. Conservation in its broadest aspects was brought to the public mind most forcibly, and the lesson applied to other species of animals as well as the buffalo.

Not so now. The buffalo are in the almost inaccessible Wood Buffalo Park. Out of sight, out of mind. A public that needs constantly to be educated about the need for conservation has almost forgotten about the buffalo and the successful effort to preserve them. Except for an article about anthrax killing some buffalo or a news item about a commercial company wishing to develop mineral resources in the Park, little is heard about the buffalo or their park.

The Wainwright Buffalo Park was closed during World War II and the area devoted to the training of military personnel, a decision dictated by national necessity in a time of emergency which can be excused on those grounds. The decision to leave the buffalo in banishment for 20 years after the war's conclusion cannot be so excused. The government's investment is lost on one hand; the public's education is neglected on the other.

A more thorough banishment can hardly be imagined. True, a few head of buffalo may be seen in the wooded confines of Elk Island Park, or in the tiny paddock at Banff. But in neither of these places do the buffalo appear in their typical natural habitat mentioned so often in the writings of the explorers and early prairie travellers. Nowhere can a boy or girl thrill to the sight of herds of buffalo like those that once roamed over the broad grassy sweep of the prairies.

We now have to persuade our children that the buffalo once existed here. Even the dinosaurs of remote ages have fared better in this respect. In the Steveville area a deliberate and successful attempt is being made to show the public that the area in which we live was once the home of these giant reptiles. In Calgary an imaginative effort has been made to recreate this remote age by means of dinosaur models. The impact of Dinosaur Park in Canadian education has been tremendous.

But the dinosaur is extinct. One can come away from Dinosaur Park without having been taught a lesson in conservation. The buffalo was rescued from extinction, as many species nearly extinct today might be if the general public could be aroused to assist in the work. However, with the buffalo out of sight in Wood Buffalo Park, the lesson is forgotten.

The buffalo were the mainstay of the primitive economy which flourished here before the white man came; careless slaughter caused the near extinction of the plains buffalo and finished forever the primitive culture that depended upon it. Our children should know this. An accessible buffalo park in the Great Plains region, the buffalo's natural home, would remind us of their part in our prairie culture.

Now there is, in my opinion, an area admirably suited to the establishment of such a park - the area in eastern Alberta near the Neutral Hills and Sounding Lake. This area has many advantages. First, and most important, it has the elements basic to buffalo survival, grass and water. A herd of buffalo could be kept there as easily as at the Wainwright Park. Also, this area retains much of the appearance of the virgin prairie. Second, the Neutral Hills to the west of Sounding Lake and another range to the south of Sounding Lake would provide a natural grandstand for visitors to the park. Furthermore,

\footnotetext{
* This brief supporting the establishment of a Neutral Hills Buffalo Park was submitted several years ago to provincial and federal government departments. We print it here because it represents an individual's active concern about the preservation of our natural heritage.
} 


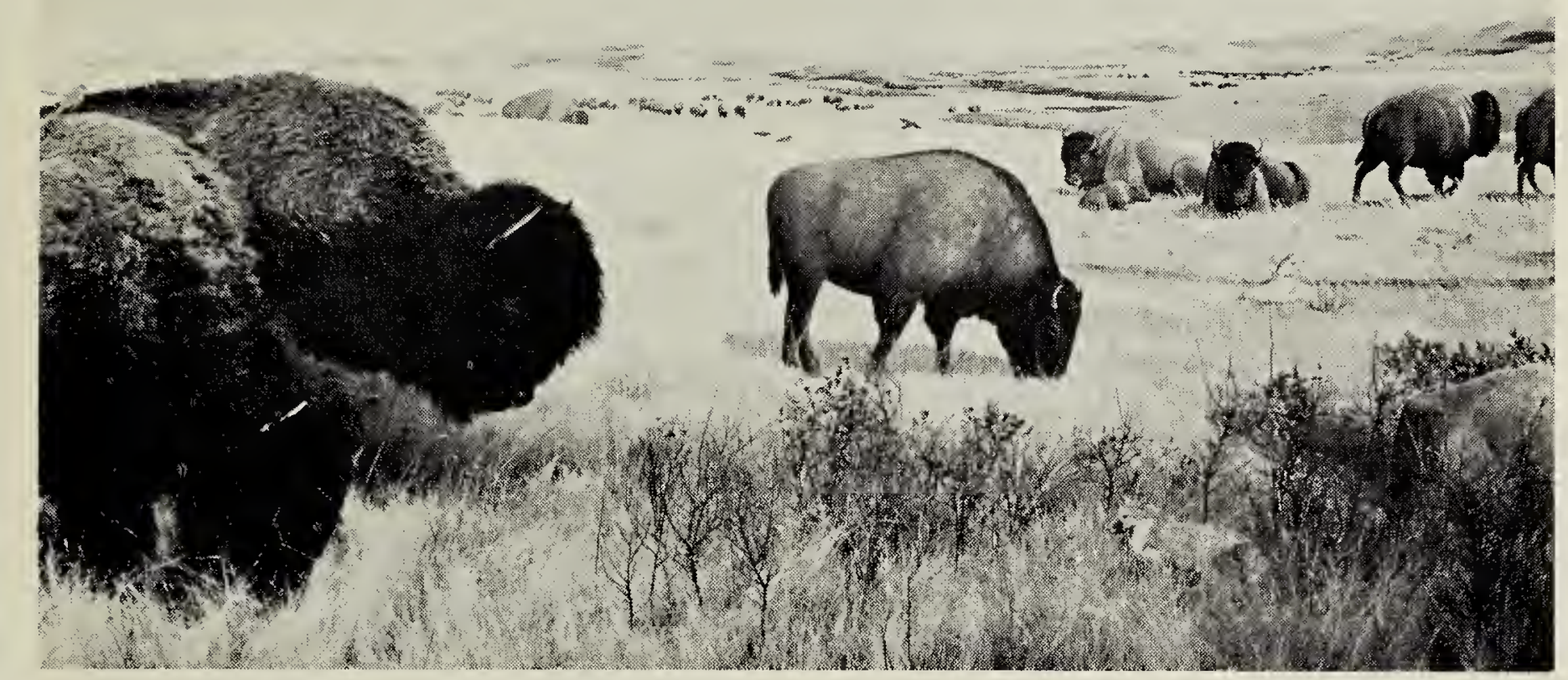

Sask. Govt. photo

From the buffalo habitat exhibit, Sask. Museum of Natural History

there are historic reasons for the establishment of a park here, reasons connected with the disappearance of the primitive Indian economy mentioned above. Finally, the area is very sparsely settled at present. The establishment of a park here would make less disturbance to an established economy than in any other place in Alberta accessible to the travelling public.

I remember a feeling of disappointment when I was taken as a child to the Wainwright Park. It seemed that my father drove up and down and around endless little hillocks in search of the buffalo. Then, suddenly, without warning, we were right among them, and curiosity turned to fear as I wondered what these large beasts would do to us. I realize now that I was watching in vain for the view of the buffalo that my reading in school had led me to expect.

From the Neutral Hills one can see for miles. A herd grazing would be clearly visible from a number of directions and at a considerable distance. A person who takes the trouble to climb any of the hills is rewarded by a view similar to that from a lowflying aircraft. The Indians realized the hunting advantages these hills offered, and remains of their signalfire places may be found on certain of the high hills to this day. Incidentally, the name Neutral Hills is said to come from a Cree legend that Manitou set the hills in place as an area in which Blackfoot, Assiniboine and Cree could hunt but must not molest each other while hunting. When they were in the hills they must act as though they were in neutral territory. Hence the name.

It is worth noting that both Nose Hill, some miles to the west, and Flagstaff Hill, many miles to the northwest, are visible from the Neutral Hills. To the south lies open prairie for many miles.

There is an historical reason for establishing a park in this area. East of Sounding Lake part of Treaty Number Six was signed with the Crees in 1878. The spot was chosen as it was often the gathering place for the Crees in certain seasons of the year. Big Bear was there, LieutenaniGovernor Laird was there from Battleford, and Assistant Commissioner Irvine and a detachment of Mounties came north from Fort Walsh for the signing. Good supplies of wood and water were available there so the Mounted Police chose a spot for the building of a barracks, whose remains may still be found. Also, ruts of the trail to Battleford may still be seen. Very few people know that such an historic site exists in eastern Alberta. Its development as part of a park is appropriate to remind our people of these events in our country's history. 
An incidental result of the setting aside of a park here would be the creation and maintenance of a sanctuary for birds. The Sounding Lake area is near the flyway of a number of species of birds including, I understand, the Whooping Crane. Such a sanctuary is badly needed by many species. The area to the south and west is becoming well known as "goose country" and attracts hundreds of hunters each fall. The country to the east in Saskatchewan is fairly intensively cultivated, leaving all too few places of safety for migrating birds. It should be noted that many birds of no real interest to the hunter are killed each year simply because they are migrating while hundreds of armed men are about, attracted by "goose country." Protected areas of the kind envisioned here provide places for birds to stop and rest in safety on their long trip south.

Population is sparse in the 12 townships under study. One township (37$4 \mathrm{w} 4)$ in which Sounding Lake is located contained no population at all when the survey was made in 1961. Seven of the 12 suggested townships have fewer than one person per square mile. Indeed, the average population for the 12 suggested townships is .756 persons per square mile. The chief activity is ranching, and much of the land is crown land available for lease to local ranchers. It is recognized that the presence of any population at all presents a problem in a proposed park area, but the difficulties presented by such a small density of population should not be insuperable.

A natural gas pipeline grid underlies much of the area, but there is no reason why this development, aiready complete, should inhibit the use of the area as a park, any more than it now inhibits the use of land for grazing.

Alberta Highways \#12 and \#13, and Saskatchewan Highways \#14, \#31 and \#51 give access to the area. Several good gravelled roads pass north and south through the area. What is particularly important, at least two of these bring the visitor into the Neutral Hills where excellent views of the surrounding country may be obtained.

In this brief I have laid stress on bringing the buffalo back to the prairies where our people can see them. I have stressed the importance of teaching conservation and of reminding Canadians of important incidents in their country's history. May I close with the suggestion that Indians be employed where possible, both as workmen and as guides. It may also be possible to find Indians who would be interested in the administration of the park. Including Indians will ensure that the part the Indians played in our country's past - and are playing today - will be suitably acknowledged as a living reality.

Indians, Mounties, the buffalobasic ingredients in the history of the Canadian West. What better place for Canadians to see them together than at a Neutral Hills Buffalo Park!

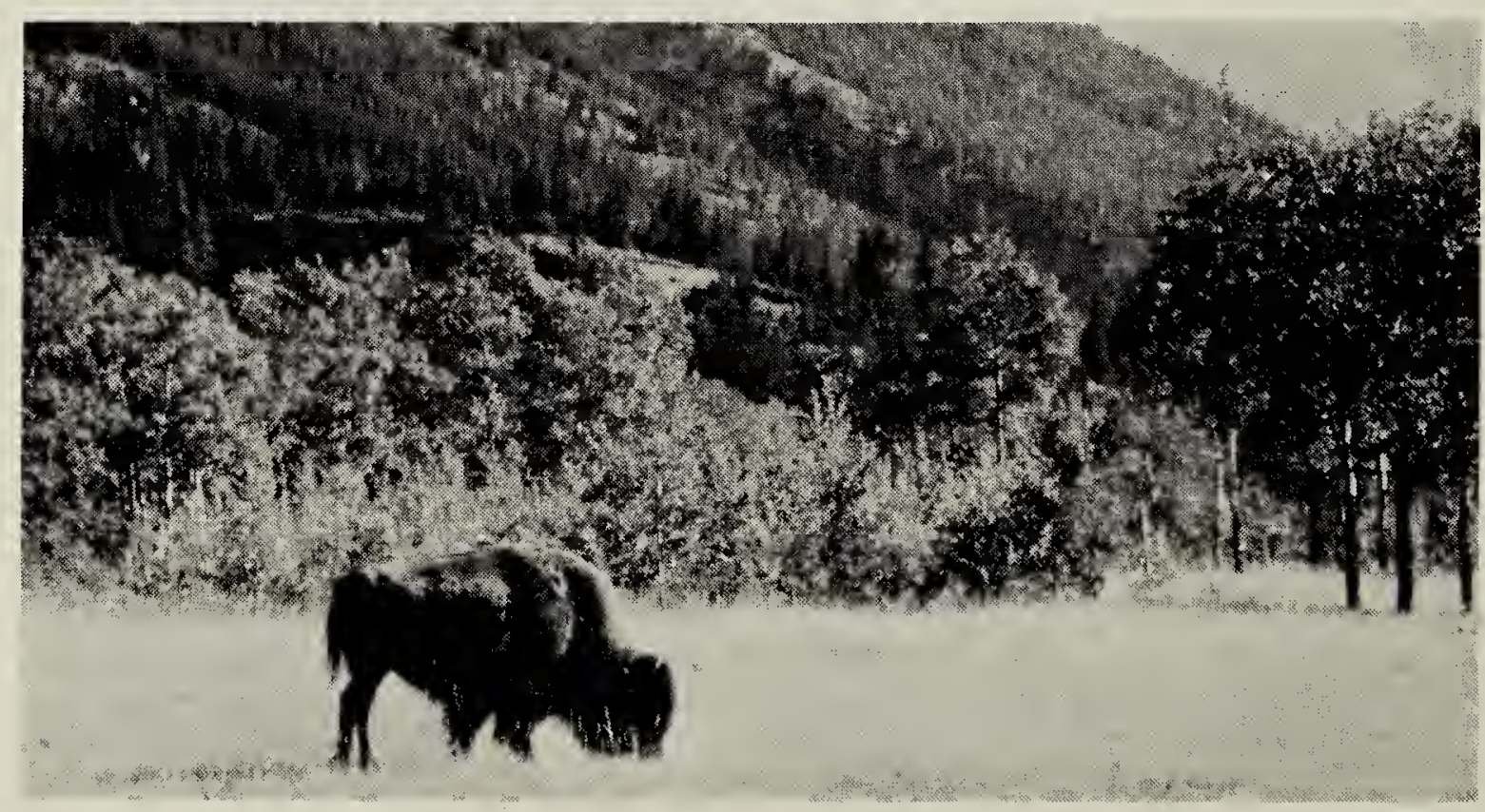

Buffalo at Banff National Park

Photo by Robert R. Taylor 